\title{
Massive Intracellular Biodegradation of Iron Oxide Nanoparticles Evidenced Magnetically at Single Endosome and Tissue Levels
}

François Mazuel ${ }^{1}$, Ana Espinosa ${ }^{1}$, Nathalie Luciani ${ }^{1}$, Myriam Reffay ${ }^{1}$, Rémi Le Borgne ${ }^{2}$, Laurence Motte 3 , Karine Desboeufs 4 , Aude Michel5, Teresa Pellegrino6, Yoann Lalatonne ${ }^{3,7}$, Claire Wilhelm ${ }^{1 *}$.

1. Laboratoire Matière et Systèmes Complexes (MSC), UMR 7057, CNRS and Université Paris Diderot, 75205 Paris Cedex 05, France.

2. ImagoSeine, Electron Microscopy facility, Institut Jacques Monod, CNRS UMR 7592, Université Paris Diderot, Sorbonne Paris Cité, Paris, France.

3. Inserm, U1148, Laboratory for Vascular Translational Science, UFR SMBH, Université Paris 13, Sorbonne Paris Cité, F-93017 Bobigny, France.

4. LISA, CNRS UMR 7583, Université Paris-Diderot \& Université Paris-Est Créteil, Créteil, France.

5. Sorbonne Universités, Physicochimie des Electrolytes et Nanosystèmes InterfaciauX (PHENIX), UMR 8234, Université Pierre et Marie Curie UPMC-CNRS, 75252 Paris cedex 05, France.

6. Istituto Italiano di Tecnologia, I-16163 Genoa, Italy.

7. Service de Médecine Nucléaire, Hôpital Avicenne Assistance Publique-Hôpitaux de Paris F-93009 Bobigny, France. 


\section{ABSTRACT}

Quantitative studies of the long-term fate of iron oxide nanoparticles inside cells, a prerequisite for regenerative medicine applications, are hampered by the lack of suitable biological tissue models and analytical methods.

Here we propose stem cell spheroids as a tissue model to track intracellular magnetic nanoparticles transformations during long-term tissue maturation. We show that global spheroid magnetism can serve as a fingerprint of the degradation process and we evidence a near-complete nanoparticle degradation over a month of tissue maturation, as confirmed by electron microscopy. Remarkably, the same massive degradation was measured at the endosome level by single-endosome nano-magnetophoretic tracking in cell-free endosomal extract. Interestingly, this spectacular nanoparticles breakdown barely affected iron homeostasis: only the genes coding for ferritin light chain (iron loading) and ferroportin (iron export) were upregulated two-fold by the degradation process. Besides, the magnetic and tissular tools developed here allow screening the bio-stability of magnetic nanomaterials, as demonstrated with iron oxide nanocubes and nanodimers. Hence stem cells spheroids and purified endosomes are suitable models needed to monitor nanoparticle degradation in conjunction with magnetic, chemical and biological characterizations at the cellular scale, quantitatively, in the long term, in situ and in real time.

\section{KEYWORDS}

Iron oxide nanoparticles, Nano-magnetism, Biodegradation, Iron metabolism, Endosomes, Stem Cells, Spheroids. 

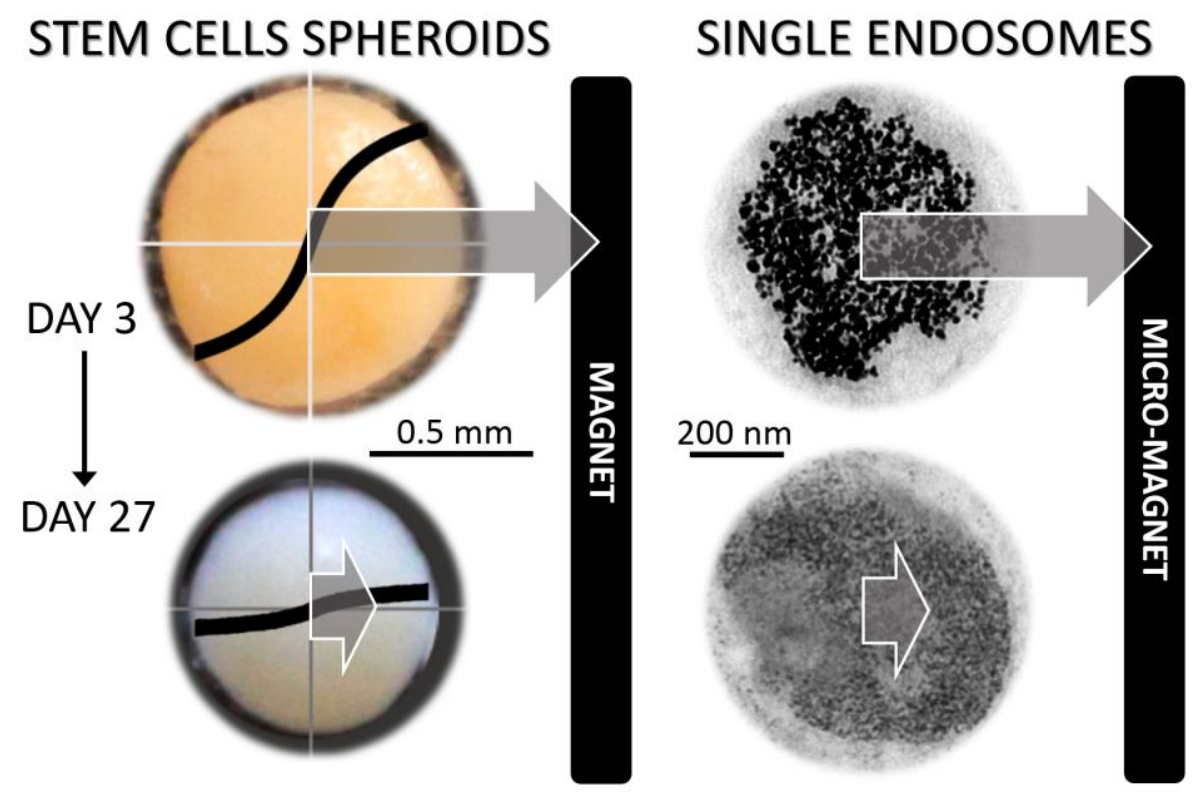

Tissue-like spheroids were used to monitor the fate of iron oxide nanoparticles incorporated inside stem cells. The in situ magnetic signatures of nano-transformation at the endosome and tissue scales showed massive (intra)cellular degradation of the nanoparticles. 
Magnetic nanoparticles have unique physical and chemical properties, placing them at the leading edge of the emerging field of nanomedicine. For regenerative medicine applications, these magnetic nanoparticles have been largely exploited as cellspecific MRI contrast agents $^{1}$ in order to track stem-cell homing after injection/implantation in vivo. ${ }^{2-7}$ More recently, it was demonstrated that remote manipulation with external magnets (magnetic targeting) can allow magnetically labelled cells to be retained at their site of implantation in vitro ${ }^{8}$ and in vivo (e.g. the heart 9,10$)$, and can be used to engineer organized tissues in vitro. ${ }^{11-15}$ Most applications of magnetic nanoparticles for regenerative medicine and cell therapies require the targeted cells to internalize them. It is then admitted that nano-cytotoxicity must then be carefully considered, as certain features of nanoparticles might entail drawbacks or even dangers. ${ }^{16}$ It was recently demonstrated that the coating, size and stability of magnetic nanoparticles, as well as an excessive intracellular iron dose, can affect cell morphology, signalling processes,${ }^{17-19}$ and stem cell differentiation. ${ }^{20,21}$ Yet, when used in properly controlled conditions, magnetic nanoparticles are efficiently taken up by stem cells without affecting their functions or their capacity for differentiation. ${ }^{21}$ However, all previous nanotoxicology studies focused solely on direct cytotoxicity, immunogenicity or genotoxicity. By contrast, the long-term intracellular degradation of nanoparticles has never been quantified, because quantitative methods for real-time tracking the biostability in the cellular environment are still missing. ${ }^{22}$

So far, attempts to quantitatively monitor the degradation of magnetic nanoparticles have used aqueous solutions to mimic the intracellular medium (acidic conditions and iron-chelating agents). ${ }^{23-26}$ At the opposite extreme of biological complexity, living animals have been used to study the fate of magnetic nanoparticles 
and other nanoparticles on organs sites. ${ }^{27-32}$ However, the complexity of the organism, the interplay between the different organs, and the body clearance prevent any measure of degradation at the (sub)cellular scale. Suitable biological models are therefore needed to monitor nanoparticle degradation at the cellular scale, quantitatively, in the long term, in situ, in real time, and reduce the gap between measurements in liquid and observations at the body scale.

The objective here was thus to go beyond classical short-term tests of cellular nano-toxicity on cell cultures, by bringing in approaches for examining magnetic nanoparticle intracellular transformations in the long term (at least a month). To do so, we developed spheroids composed of stem cells having incorporated iron oxide (citrate-coated) nanoparticles and we demonstrated that it was a suitable model to monitor biodegradation of nanoparticles. Magnetic approaches, in conjunction with chemical and biological characterizations, were used to follow the magnetic, structural and biochemical fate of the internalized nanoparticles, within their tissue-like environment. The kinetics of degradation was measured as the loss of nano-specific magnetic properties and intracellular transformations were tracked at the nanoscale. A cell-free endosome model was developed as well to monitor the degradation at the single endosome scale. All measures point towards an unexpected massive biodegradation of the iron oxide nanoparticles at endosome sites. The impact of such iron degradation on iron homeostasis was thus assessed. Finally, these experimental approaches were readily transferred from spherical shaped citrate coated iron oxide nanoparticles to other iron oxide nanomaterials with different shapes (nanocubes), compositions (gold/iron oxide nanodimers), and coatings (PEG chains or polymer coating). 


\section{RESULTS \& DISCUSSION}

\section{A minimal, long-term-viable model tissue}

We developed a model tissue to track quantitatively, in real time, and on the long term, intracellular nano-bio-transformations. Inspired by the chondrogenic differentiation process, this tissue model is composed solely of human mesenchymal stem cells (MSC), in the form of spheroids in which the cells ( 200 000) stop dividing and start producing a collagen-rich extracellular matrix. Prior to spheroid formation, MSC cells were incubated with iron oxide nanoparticles (citrate coated, mean diameter $8 \mathrm{~nm}$ ), leading to a magnetic load of 2 million of nanoparticles per cell (equivalent to $2 \mathrm{pg} F$ corresponding to usual doses for use in cell imaging. ${ }^{33-35}$ Each of the MSC cells composing the spheroid thus contains iron oxide nanoparticles confined within endosomes. Illustrations of the spheroid formation and maturation process are presented in Figure 1A. During the first day of maturation, the cell pellet formed by centrifugation rounds up to form a spheroid and compact (see supporting Figure S1 for the average size decrease over a month). These tissue-like spheroids can be maintained over a month with no core necrosis, as observed on histological sections stained with hematoxylin eosin (Figures 1B and S2), and on confocal immunofluorescence images (Figures 1C and S3) of both the actin network and cell-cell adhesion patterns (Ecadherins). These strengthened E-cadherin bonds reflect the cohesiveness and integrity of the tissue. After 27 days of spheroid maturation, genes coding for extracellular matrix components (collagen II and proteoglycans) are overexpressed (Figure S4). Collagen fibers are also clearly seen on sections observed by transmission electron microscopy (TEM, Figure 1D). All these observations further validate the spheroids as a model 
tissue combining viability, cohesiveness, integrity and a rich extracellular matrix, while nanoparticles are initially embedded within the tissue, confined inside intracellular endosomes at the heart of the MSC component cells (Figure 1D).

\section{Magnetic fingerprints of intracellular biodegradation at the tissue scale}

The next challenge was to develop methods to quantitatively monitor at a macroscopic level some potential intracellular biodegradation. The idea is to use the spheroid magnetic signature related to the superparamagnetic features of the nanoparticles embedded within it to track the amount of intra-tissular still intact nanoparticles over the maturation time. Comprehensive magnetic approaches were thus implemented to monitor the spheroids' magnetism in situ. First, a magnetophoresis technique was developed to measure the macroscopic magnetization of a single spheroid. The spheroid was placed within a calibrated magnetic field gradient (gradB=17.5 T/m) created by a permanent magnet $(B=1500$ Oe). The magnetic force, proportional to the magnetic moment and to the magnetic field gradient, is equilibrated by the drag force. The spheroid magnetic moment is thus retrieved by measuring its limit velocity and size (see Materials and Methods, and Figure S5). Magnetophoresis brings the advantages of simplicity, low cost, and real-time measurements. Figure 2A shows typical spheroid magnetic migrations at different stages of the maturation process (day 3, day 9 and day 27). It clearly illustrates that the velocity, and thus the magnetic moment, collapses with time, evidencing a loss of magnetic features provided by intact nanoparticles.

Single spheroids' magnetic moments were also determined by magnetometry measurements, using a vibrating sample magnometer, VSM. Magnetometry was recently used to investigate the magnetic properties of nanoparticles once internalized within cells. ${ }^{36}$ Figure 2B shows the retrieved magnetic moment of a single spheroid at different times of the maturation process (see also Figure S6 which illustrates the reproducibility 
of the measurements). The spheroid magnetic moment clearly collapsed during the maturation process: at day 27 , it has lost about $90 \%$ of its initial value. Magnetometry not only provides the absolute magnetic moment of the spheroids; it also indicates the size distribution of the nanoparticles within the sample (see Materials and Methods). Figure $2 \mathrm{C}$ shows that the renormalized spheroid magnetization curves on different days of tissue maturation were remarkably similar to the initial curve of the nanoparticles in aqueous dispersion. This demonstrate that the nanoparticle size was not impacted and that the degradation, when it occurs, follows an all-or-nothing mechanism, nanoparticles being either totally dissolved, or left intact.

\section{Massive collapse of spheroid magnetization over time: a total nanoparticles} resorption.

The magnetic moments can be directly converted into a mass of iron (see Methods for details), that we call "magnetic iron" because it reflects the amount of iron responsible for the superparamagnetic properties. Figure 2D shows the average spheroid magnetic iron values obtained by magnetophoresis and magnetometry as a function of the

maturation time. Note that the two magnetic measurements are in remarkable agreement. In average, the spheroids showed a dramatic decrease in their magnetic iron, losing more than $90 \%$ of their initial value. The decline was rapid, with a $50 \%$ decrease after 3 days.

The question was then whether this decrease was due not only to nanoparticle degradation within the tissue, but also to nanoparticle expulsion from the tissue. Magnetic measurements were thus compared to the total iron atomic content (ICP). The total iron content was remarkably stable over the course of the maturation process, and equaled the value of magnetic iron on day 0 . This indicates that no nanoparticles are 
expulsed, and that the iron atoms released by nanoparticle degradation remained within the spheroid. It also highlighted that no cells were lost during maturation.

\section{Long-term imaging (TEM and histology) of intracellular nanoparticle degradation} within the model tissue

TEM is the method of choice for in situ nanoscale location of nanoparticles within the model tissue and its component cells, and for monitoring their individual fate as a function of tissue maturation. Figure 3 shows TEM images of the tissue on day 0 (3A, tissue formation) and after 27 days of maturation (3B, additional images are shown in Figure S7, including observations at day 3). At day 0, all nanoparticles were located within endosomes, with a mean diameter measured at $d_{\text {tem }}=9.4 \pm 2.6 \mathrm{~nm}$ (size distribution shown in Figure S8), corresponding to the initial size and polydispersity of the nanoparticles prior to cell incorporation (see also Figure s8 for the initial nanoparticle size distribution). At day 27, only rare nanoparticles were still detected within endosomes (unchanged size distribution, average diameter $d_{\text {tem }}=9.4 \pm 2.6 \mathrm{~nm}$, Figure S8). By contrast, a large number of smaller electron-dense spots emerged within the cytoplasm, revealing the probable loading of ferritin (intracellular iron storage protein) with free iron ions. ${ }^{37}$ Indeed, after storing iron (up to $4500 \mathrm{Fe}^{3+}$ ions), ferritin scatters electrons and can be identified ${ }^{38,39}$ directly in the form of small $(5-7 \mathrm{~nm})$ dark spots (albeit less dark than the whole nanoparticles). Here, the smaller, less dark, spots revealed after image analysis an average diameter of $5.8 \pm 0.7 \mathrm{~nm}$ (size distribution shown in Figure S9), confirming them to be iron-loaded ferritin. This loaded ferritin was either found within endosomes (Figures 2B4\&5) or distributed throughout the cytosol (Figure 2B6). In rare endosomes, loaded ferritin coexisted with intact nanoparticles (Figure 2B2\&3). Note that at day 0 none of this spots identified as loaded ferritin can be seen in the cytosol (Figure 2A3). These observations and measurements confirm the 
massive degradation measured macroscopically by magnetism and indicate that, after 27 days of tissue maturation, (i) a very large fraction of the initial nanoparticles has been degraded, (ii) the iron ions released by this process are stored within the ferritin cage, and (iii) degradation occurs on an all-or-nothing basis: nanoparticles are either totally dissolved or wholly intact.

The delivery of free iron ions from the endosomes to the cytosol, and their transfer to ferritin, can also be seen on histological images after Prussian Blue staining, which is specific for all forms of iron. Figure 3C shows sections of spheroids at different stages of maturation. On day 0, well-defined blue spots are found in cell cytoplasms, corresponding to endosomes filled with nanoparticles. As maturation progresses, the spots become more diffuse: when nanoparticles degrade, part of the iron escapes from the endosomes and is captured by cytosolic ferritin. At day 27, the cell cytoplasm exhibits a diffuse blue color, with only scarce blue spots. These observations closely match TEM images showing abundant ferritin in the cytosol (light blue) and some ferritin inside endosomes (dark blue spots).

\section{Quantitative magnetic monitoring at the single endosome scale}

From day 0 , the nanoparticles appeared to be localized within endosomes, which would therefore be the site of the degradation process. However measuring biodegradation on single endosomes is still missing. To fill this gap, we conceived a minimal cell-free endosomes-only system. Endosomes were successfully extracted (magnetically) from the stem cells on day 0 , just before they would be used to form a spheroid (see Materials and Methods). The pH of this minimal endosomal system was adjusted to 7 or to 4.7, to mimic the acidity of the intraendosomal (lysosomal) medium. The magnetic moment of single endosomes could then be tracked over time by magnetophoresis, at the microscopic scale, using a magnetic microtip to amplify the magnetic field gradient. 
Using this micromagnetophoretic set-up, we monitored the motions of 100 magnetic endosomes in the direction of the magnetic field gradient on days $0,3,9,20$ and 60 after extraction (Figure 4A and Figure S10), and converted their velocity into a mass of magnetic iron. The average mass of iron per endosome (m) was then calculated, as well as the width of the distribution of this mass over the endosome population $(\Delta \mathrm{m})$, on the different days (a typical distribution is shown in Figure S10). Figure 4B (and Figure S10) shows the evolution of $\mathrm{m}$ and $\Delta \mathrm{m}$ (respectively) over days $0,3,9,20$ and 60 . First, at $\mathrm{pH}$ 7, the mean mass of magnetic iron contained within the endosomes decreased, to $50 \%$ of its initial value during the first 10-20 days after extraction. When the medium was buffered at $\mathrm{pH} 4.7$, degradation was more rapid, the endosomes losing $50 \%$ of their initial magnetic mass after 2-3 days.

Importantly, nanoparticles dispersed in the same medium, without endosomes, had lost none of their magnetization after one month (Figure 4C), even at $\mathrm{pH}$ 4.7. Only when an iron chelating agent (citrate) was added to the solution the nanoparticles did undergo degradation. These comparative results suggest that the proteases, enzymes and chelating agents necessary to degrade the nanoparticles are brought by the endosomes. Remarkably, at $\mathrm{pH} 4.7$, the rate of degradation was similar to that observed inside stem cells arranged into spheroids (compare Figure 4B with Figure 2C). The degradation monitored at endosome scale thus matched the global intracellular degradation, advocating for a central role of endosomes in the degradation process. It can thus be assumed that comparable intracellular degradation would be obtained in other cell types, including cancer cells (albeit cell division and redistribution of the nanoparticles between the daughter cells can then occur) or macrophages (albeit a higher intracellular iron dose would be reached).

\section{Biological monitoring of iron homeostasis during biodegradation}


Figures 2 to 4 illustrate nanoparticle bio-attack inside endosomes: iron is freed from the nanoparticles. A parallel biological approach was thus used to evaluate the effect of this free-iron input on the expression of genes involved in iron metabolism. During magnetic spheroid maturation, we monitored the expression of four genes coding for ferritin subunit H (Heavy chain with ferroxidase activity), for ferritin subunit L (Light chain involved in iron binding and nucleation), for ferroportin (ensuring iron export from the cell), and for divalent metal transporter DMT1 (mediating the transport of ferrous iron across membranes). Figure 5 compares, at different maturation times, gene expression in nanoparticle-labelled and unlabelled (control) spheroids. At day 3, a slight overexpression of the genes coding for ferritin L and ferroportin is observed. This overexpression progressively increases with the maturation time, in agreement with the degradation rate. Ferritin $\mathrm{H}$ gene expression was not modified by the nanoparticles (the ratio of the two ferritin subunits are variable in a ferritin complex ${ }^{39,40}$ ), which implies that no intense ferroxidase activity was required, maybe because iron was already in its oxidised state within the maghemite core of the nanoparticles. The gene expression of the divalent metal transporter 1 was as well unchanged by nanoparticle exposure.

The few previous studies of the impact of intracellular transformation of iron oxide nanoparticles on iron homeostasis gave similar results. In some cases, iron homeostasis was slightly impacted by magnetic nanoparticle internalisation, with the upregulation of iron-storage and/or iron-export proteins, ${ }^{41-44}$ and in some cases the down-regulation of proteins involved in iron intake (such as TFR1). ${ }^{45}$ However, it is important to emphasize that the majority of these studies never lasted more than a few days after nanoparticle incorporation. Here, during the first days after nanoparticles internalization, the increase in ferritin L and ferroportin expression was small, becoming really significant 
$\left.{ }^{* *}\right)$ only after 9 days or 27 days, respectively. Besides, even at 27 days, we recorded only a doubling of ferritin $\mathrm{L}$ and ferroportin gene expression, with no impact on the regulation of ferritin $\mathrm{H}$ or DMT1, suggesting that the cell machinery barely needed to be activated in order to take up the iron delivered by the nanoparticles within its endogeneous iron pool.

A model suitable for any magnetic nanoparticles intracellular biodegradation: application to iron oxide nanocubes and gold/iron oxide nanodimers

To demonstrate the potential of the magnetic and tissular tools, described here, for the screening of different nanomaterials bio-stability, beside using citrate coated iron oxide nanoparticle, we also tested two different magnetic nanostructures. Both exhibit specific features, namely a particular geometry (cubic or dimeric) and different surface coating (a PEG polymer or an amphiphilic polymer coating). The iron oxide nanocubes are $20-\mathrm{nm}$ in cube edge and were made water soluble by a gallic-PEG shell. ${ }^{46}$ The nanodimers are composed of a $10-\mathrm{nm}$ maghemite nanoparticle stuck by a small interface, to a 3.5-nm gold particle and they were transferred into water by encapsulation in a shell of amphiphilic alkyl modified polymaleic polymer. ${ }^{47}$ The welldefined shape of the nanocubes enables any structural modifications to be observed precisely, while the gold seed of the nanodimers provides a metallic tracer, gold being non degradable. ${ }^{48}$

Figures $6 \mathrm{~A}$ and $6 \mathrm{~B}$ show TEM images of the cubic and dimeric nanostructures on day 0 and day 27 of tissue maturation. Figures S11 and S12 show additional images at days 0, 3 and 27. All the nanocubes (Figure 6A) exhibited distinct square edges on day 0 , and no iron-loaded ferritin was detected, whereas on day 27 the edges sometimes appeared more rounded and ferritin was visible (clearly seen in Figures S11\&S13). On day 27, $83 \%$ of observable cubes remained intact, but some nanocubes were also probably 
totally degraded, thus unaccounted for. With the nanodimers (Figure 6B), gold was clearly visible (more electron-dense) as dark black spots attached to the iron oxide nanoparticles. On day 27, some endosomes contained gold nanoparticles alone (degraded dimers, 24\%), while other gold seeds were still attached to intact dimeric structures (76\%). Loaded ferritin was then systematically observed close to the degraded structures (see Figure 6B and Figures S12\&S13). Figure S13 illustrates the nanoparticles identification process on TEM images.

We then monitored for one month (day 0 and day 27, Figures 6C\&D) the magnetic iron (typical magnetization curves are shown in Figure S14) and total iron content of stemcell spheroids containing nanocubes or nanodimers, with an iron initial load similar to that used for the nanoparticles. The total iron content remained the same in all conditions, whereas the magnetic iron mass fell by $27 \%$ with the nanocubes and $20 \%$ with the nanodimers. As expected, the $27 \%$ decrease observed with the nanocubes was larger than the proportion of intact cubes measured on TEM images, as totally degraded nanocubes could not be counted on TEM images but contribute to the overall decrease in magnetic measurements. By contrast, the proportion of intact nanodimers relative to the proportion of gold seeds freed of their iron oxide moiety (24\%) corresponded to the global degradation measured at the tissue scale (20\%).

Renormalized magnetization curves are shown in Figures 6E\&6F, giving insights into magnetic size and interactions. Note the hysteresis opening revealing strong confinement of nanocubes within endosomes (ferromagnetic core), which further increased during tissue maturation. With the nanodimers (superparamagnetic core), the magnetization curves were similar to those obtained with the nanoparticles, again demonstrating an all-or-nothing degradation mechanism for the iron oxide component (magnetic diameters and polydispersity $\sigma$ are shown in Figure S14), and corroborating 
the TEM observations of dimeric structures with either an intact iron oxide core or isolated gold seeds with no iron oxide remnant.

Finally, the efficiency of nanocubes and nanodimers degradation (26.8\% and $20 \%)$ was low compared to the $90 \%$ decrease observed with the nanoparticles, demonstrating that both complex nanostructures are much more resistant to degradation.

At last, it should be noted that the stem cells spheroids developed here to monitor magnetically any intracellular iron oxide nanoparticles biodegradation can be translated to the study of other non-magnetic nanomaterials, presuming that global measurements could be implemented at the spheroid scale (e.g photothermal imaging for plasmonic nanoparticles; optical imaging for luminescent nanoparticles).

\section{Quantitative intracellular fate of magnetic nanoparticles in a biological tissue}

The emerging field of nanomedicine recognizes that consensus on the use of nanoparticles for diagnostics or therapeutics purposes can only be reached on the basis of a sound understanding of the response of nanoparticles to the biological environment. Besides, it is now admitted that investigating the safety assessment of nanoparticles should not be limited to immediate nano-toxicological tests after nanoparticles exposure, but at the opposite that systematic studies of the long-term biokinetics of nanoparticles transformations in the biological environment are now mostly needed. ${ }^{49}$ Because most theranostic applications need nanoparticles to be taken up by the cells, intracellular nanotransformation (nanodegradation) must then be fully characterized, especially in the long term. Such studies come up against two main difficulties: the need for a biological model and for macroscopic indicators that can be used to quantify changes at the tissue scale, correlating with nanoscopic observations.

Multicellular spheroids have recently undergone major interest for studying tumor behavior, ${ }^{50,51}$ for investigating tissue mechanics, ${ }^{52}$ for testing drugs delivery (including 
nanoparticles),53-56 or for evaluating the toxic response of materials (in particular nanoparticles). ${ }^{56,57}$ Spheroids overcome multiple shortcomings of classical 2D cultures, the most important being that $2 \mathrm{D}$ culture condition does not reflect the native tissue structures (e.g. cell-cell and cell-matrix interactions, cell shapes and functions). These recent biomimetic 3D tissue models generally incorporate cancer or stromal cells, all of them undergoing multiple rounds of cell division once organized within the spheroids, thus precluding from monitoring the spheroids properties on the long-term (over a few days). By contrast, stem cells spheroids provide a valuable model for monitoring longterm features. The stem cells in these spheroids stop dividing (thus the spheroid size does not increase, and the iron content per cell remains constant) and start to differentiate and actively secrete extracellular matrix components, remaining viable over months.

Here we demonstrate that stem cell spheroids can be used to monitor the fate of iron oxide intracellular nanoparticles over a month, and that one single spheroid's magnetism is a quantitative fingerprint of intratissular (/cellular) nanotransformations. Because the spheroids magnetism is directly related to the superparamagnetic features of the nanoparticles embedded within, the magnetic signature not only tells the amount of remaining nanoparticles, but also provides insight into their design (size and polydispersity) over the time course of their degradation. Interestingly, all magnetization curves (hysteresis loops at $300 \mathrm{~K}$ ), normalized to the saturation magnetization, were identical, whatever the period of tissue maturation (day $0,3,9$ or 27). This indicates that the size distribution of the remaining nanoparticles was not modified, and that no partially degraded nanoparticles (smaller in size) can be detected. This finding was confirmed by TEM images analysis of the nanoparticles size distribution. The exact mechanism of nanoparticles degradation still remains unclear, 
but one probable explanation would be that once approached by iron chelating agents in the intracellular environment, nanoparticles completely dissolve, while others, with less local accessibility, remain intact. Interestingly, the same finding was made for iron oxide / gold nanodimers, where the iron oxide part either totally disappear, or remains intact. Besides, in such case, the total dissolution of the iron oxide was further confirmed by TEM images, where only intact dimers (same sizes) or single gold nanoparticles (no more iron oxides), were detected. Importantly, the iron oxide nanoparticles in the nanodimers have a similar size $(10.7 \mathrm{~nm})$ than the one of the iron oxide nanoparticles only $(9.4 \mathrm{~nm})$, potentially explaining their common all-or-nothing degradation mechanism. By contrast, for the iron oxide nanocubes also investigated here, much larger in size (cubes of $20.5 \mathrm{~nm}$ edges), degradation can partially occur, leaving some smaller particles, roughly spherical. These attacked nanocubes were mostly found at the endosomes edges (rarely in the centre), in agreement with the vision that iron chelating agents must have facilitated access to trigger degradation. Another important finding concerns the role of the nanoparticles coating. Here again, nanoparticles (simple citrate molecule coating) and nanodimers (polymer coating) are interesting to compare because similar in size (the iron oxide in nanodimers is 1.1 larger in diameter, 1.3 in surface, compared to nanoparticles). While almost all nanoparticles can be degraded ( $>90 \%$ ), only $20 \%$ of the nanodimers (the iron oxide part) are dissolved over time. This is thus essentially due to the protective polymeric coating. By contrast, for iron oxide nanocubes (with PEG coating), where about 30\% are degraded, the protection to degradation compared to spherical nanoparticles can be due to both (or either) the coating and the important surface increase $\left(1110 \mathrm{~nm}^{2}\right.$ for nanoparticles, $2520 \mathrm{~nm}^{2}$ for nanocubes). 
Finally, the most important finding here is the massive degradation found for the iron oxide nanoparticles citrate coated, at endosome sites, together with the evidence that the excess of free iron thus generated can be oxidized, mineralized, and sequestered within the iron-storage ferritin, limiting in return any toxic oxidative response. The fate of the iron-loaded ferritin still remains to be investigated.

\section{CONCLUSION}

The quantitative long-term fate of intracellular magnetic nanoparticles is largely unexplored, yet this knowledge is mandatory to predict their clinical safety.

We show that it is possible to quantify, with magnetic methods, the intracellular degradation of magnetic nanoparticles incorporated into stem cells composing a tissuelike structure. This quantitative magnetic monitoring revealed massive biodegradation within endosomes in less than a month, showing that a tissue can quickly purge itself of such nanoparticles. Interestingly, we observed the same massive biodegradation at single endosome scale. Besides, the subsequent intracellular release of iron ions loads ferritin without only slightly affecting cellular iron homeostasis.

These findings are reassuring for medical applications, particularly in regenerative medicine, where the fate of nanoparticles present within an engineered tissue is clearly a critical issue.

Finally, the stem-cell model tissue developed here can be used to follow the intracellular fate of any type of nanoparticle, as shown here for nanocubes and nanodimers, allowing to screen the biostability of nanoparticles within their intracellular target.

\section{MATERIALS AND METHODS}




\section{Citrate-coated iron oxide nanoparticles}

Maghemite nanoparticles synthesized by coprecipitation were chosen, as they are the magnetic nanoparticles most commonly used in nanomedicine. Briefly, the ionic precursor was produced by alkaline coprecipitation of iron (II) chloride and iron (III) chloride. The colloidal magnetite $\left(\mathrm{Fe}_{3} \mathrm{O}_{4}\right)$ thus obtained was chemically oxidized into maghemite $\left(\gamma-\mathrm{Fe}_{2} \mathrm{O}_{3}\right)$ and dispersed in water. The maghemite nanoparticles were then chelated with citrate, which complexes with the nanoparticles' ferric oxide surface. Citrate chelation confers negative surface charges due to the carboxylate groups, sufficient to ensure their stability in aqueous suspension by electrostatic repulsion, with no need for a polymer coating.

The nanoparticle magnetization curves are shown in Figure 2D. Saturation magnetization was $65 \mathrm{emu} / \mathrm{g}$ of iron. The magnetization curve was fitted by a Langevin law pondered by a log-normal distribution of the particle diameter (see following Analysis of magnetization curves section). The mean magnetic diameter $\mathrm{d}_{\text {mag }}$ extracted from the fit was $d_{m a g}=8.0 \mathrm{~nm}$, with a polydispersity of $28 \%$. TEM image analysis gave $\mathrm{d}_{\mathrm{tem}}=9.4 \pm 2.5 \mathrm{~nm}$.

\section{Iron oxide nanocubes and iron oxide / gold nanodimers}

The other two nanomaterials tested here were prepared by thermal decomposition of organometallic precursors. For nanocubes, iron(III) acetylacetonate and decanoic acid were mixed in dibenzyl ether at $200^{\circ} \mathrm{C}$. The chloroform soluble nanocubes were transferred in water by exchanging the hydrophobic surfactants with a gallic-PEG coating. ${ }^{46}$ For nanodimers, a mixture of oleic acid, oleylamine, 1,2-hexadecanediol and 1-octadecene was heated at $100^{\circ} \mathrm{C} .{ }^{57}$ Iron pentacarbonyl, followed by a mixture of gold(III) chloride trihydrate, oleylamine and octadecene, was then added and the temperature was raised to $310^{\circ} \mathrm{C}$. After washing in isopropanol and re-dispersion in 
hexane, a well-established polymer coating procedure was used to enwrap the dimers in an amphiphilic polymer and made them water soluble. ${ }^{46,57}$

The magnetization curves of the two nanomaterials are shown in Figures 6E \& 6F, with saturation magnetization of $88 \mathrm{emu} / \mathrm{g}$ of iron for the nanocubes, and $70 \mathrm{emu} / \mathrm{g}$ of iron for the nanodimers. Fitting by a Langevin law pondered by log-normal distribution provided mean magnetic diameters of $\mathrm{d}_{\mathrm{mag}}=18.5 \mathrm{~nm}$ ( $17 \%$ polydispersity) for the nanocubes and $d_{m a g}=10.6 \mathrm{~nm}(20 \%$ polydispersity) for the nanodimers. TEM image analysis gave $d_{t e m}=20.5 \pm 3.2 \mathrm{~nm}$ for the cube edges and $d_{t e m}=10.7 \pm 2.2 \mathrm{~nm}$ for the iron oxide components of the nanodimers, while the gold moiety was much smaller $\left(d_{\text {tem }}=3.5 \pm 0.7 \mathrm{~nm}\right)$.

\section{Cell culture and nanoparticles internalization}

Mesenchymal stem cells (MSC, Lonza) were cultured in MSCBM medium (Lonza) at $37^{\circ} \mathrm{C}$ with $5 \% \mathrm{CO}_{2}$. The cells were amplified until passage 4 , always to $90 \%$ confluence, and then used. Nanoparticles were dispersed in RPMI medium (supplemented with $5 \mathrm{mM}$ citrate to ensure colloidal stability) at $[\mathrm{Fe}]=0.1 \mathrm{mM}$ and incubated with the cells for 30 min. After a washing step with fresh medium, the cells were left overnight to allow complete internalization. The cellular iron load (mass of iron per cell) was measured by single-cell magnetophoresis, ${ }^{21}$ giving an average value $\mathrm{m}_{\mathrm{Fe}} /$ cell $=2 \mathrm{pg}$ (polydispersity among the cell population of $40 \%$ ).

Nanocubes and nanodimers were incubated overnight with the cells at $[\mathrm{Fe}]=0.2 \mathrm{mM}$ and $[\mathrm{Fe}]=1 \mathrm{mM}$, respectively. These incubation parameters were selected to match iron capture per cell, again measured by magnetophoresis: $\mathrm{m}_{\mathrm{Fe}} / \mathrm{cell}=2.8 \mathrm{pg}$ (polydispersity $45 \%$ ) for nanocubes; $\mathrm{m} F$ /cell=3 pg (polydispersity $45 \%$ ) for nanodimers.

\section{Spheroid formation and maturation}


After incubation with the nanoparticles, the cells were detached with trypsin and washed with maturation medium. 200000 cells were dispersed in $1 \mathrm{~mL}$ of maturation medium in 15-mL centrifuge tubes and spun at $180 \mathrm{~g}$ for 2 minutes to form a pellet. The pellets were left in maturation medium at $37^{\circ} \mathrm{C}$ with $5 \% \mathrm{CO}_{2}$. The medium was changed every 3 days.

The maturation medium was composed of high-glucose, serum-free DMEM containing dexamethasone (Sigma, final concentration $0.1 \mu \mathrm{M}$ ), sodium pyruvate (final concentration $1 \mathrm{mM}$ ), ascorbic acid-2 phosphate (Sigma, final concentration $50 \mu \mathrm{M}$ ), Lproline (Sigma, 0,35 mM), ITS Premix (BD Biosciences, $1 / 100$ dilution) and TGF- $\beta 3$ at $10 \mathrm{ng} / \mathrm{ml}$.

At each time point during the maturation period (days $0,3,9,27$ and 40 ), some of the spheroids were used for magnetic measurements, electron microscopy, histology, elemental analysis, and/or gene expression quantification. We checked (data not shown) that the degradation process was stopped by the aggregate fixation, by measuring the same spheroid magnetization after a two months long storage in PBS.

\section{Transmission electron microscopy}

The spheroids used for transmission electron microscopy were fixed for 1 hour at room temperature with $2.5 \%$ glutaraldehyde in $0.1 \mathrm{M}$ cacodylate solution, then for 1 hour at room temperature with $1 \% \mathrm{OsO}_{4}$ in $0.1 \mathrm{M}$ cacodylate solution, and finally included in Epon resin after dehydration. Slices $80 \mathrm{~nm}$ thick were observed with a Phillips Tecnai 12 electron microscope.

\section{Histology}

Spheroids were fixed in formalin before being included and frozen in OCT (VWR). 8- $\mu$ m slices were prepared by cryosection and stained with Prussian blue (1\% potassium ferrocyanide in 1\% hydrochloric acid) and hematoxilin (Sigma), eosin (Sigma). 


\section{Spheroid magnetophoresis}

To measure the macroscopic magnetization (M) of the spheroids, single spheroids (previously fixed in formaline for $1 \mathrm{~h}$ ) were immersed at each time point in pure glycerol solution thermostated at $37^{\circ} \mathrm{C}$ and placed in a calibrated homogeneous magnetic field gradient $(B=150 \mathrm{mT}, \operatorname{gradB}=17.5 \mathrm{~T} / \mathrm{m})$ generated by a permanent cylindrical neodymium magnet (diameter: $25 \mathrm{~mm}$, height: $10 \mathrm{~mm}$ ). Each spheroid was thus attracted by a magnetic force $\mathrm{F}=\mathrm{MgradB}$, equilibrated by the Stoke drag $\mathrm{F}_{\text {drag. }}$ Once the equilibrium regime is reached (within seconds, Reynolds number $\operatorname{Re}=10^{-3}-10^{-4}$ ), the spheroid moves at a constant speed (V). The spheroid is an oblate ellipsoid (see Figure S5), and the corresponding drag force must be written as $F_{d r a g}=6 \pi \eta V a K$, where a is the equatorial semi axis (defined in Figure S5) and $\mathrm{K}$ is the form factor (also provided in Figure S5). For each spheroid, the small axis a and long axis b were systematically measured (2.5X objective, Leica DMIRB microscope), and the spheroid movement was video-monitored. The experiment was repeated 4 times for each spheroid. Finally, velocity was computed with Image J software on spatio-temporal diagrams of the recorded image stacks. The magnetic moment thus calculated (in A.m ${ }^{2}$, at $150 \mathrm{mT}$ ) can be converted to grams of iron from the magnetization curves providing relative magnetization at $150 \mathrm{mT}$ and the saturation magnetization in emu/g $\left(1 \mathrm{~A} \cdot \mathrm{m}^{2}=10^{3} \mathrm{emu}\right)$.

\section{Spheroid magnetometry}

At each time point, fixed spheroids were introduced in sample capsules for Vibrating Sample Magnetometer analysis (VSM, Quantum Design, Versalab). Field-dependent magnetization curves were measured at $300 \mathrm{~K}$ as a function of the external field, in the range 0 to $3 \mathrm{~T}$ (step rate of $30 \mathrm{mT} / \mathrm{s}$ ) to obtain saturation magnetization, and in the range $-150 \mathrm{mT}$ to $150 \mathrm{mT}$, with a step rate of $10 \mathrm{mT} / \mathrm{s}$, for more precise measurements. The magnetic moment thus recorded (in emu) can directly be converted into grams of 
iron thanks to the magnetization at saturation of each material (expressed in emu/g of iron).

\section{Analysis of magnetization curves: lognormal size distribution of the nanoparticles}

The magnetization curve $M(H)$ of a suspension of monodisperse iron oxide nanoparticles can be described by a Langevin formalism:

$$
M(H)=m s \phi(\operatorname{coth} \xi-1 / \xi)
$$

where $\xi=\mu 0 \mathrm{msVH} / k T$ is the Langevin parameter, $\mu 0$ the vacuum magnetic permeability, $m s$ the saturation magnetization of the magnetic material, $H$ the magnetic field, $k$ the Boltzmann constant, $T$ the temperature, $V$ the particle's magnetic volume, and $\phi$ the volume fraction of particles in the suspension. For a polydisperse sample, $M(H)$ can be adjusted by weighting the Langevin expression by a log-normal distribution of particle diameter $d$

$$
P(d)=\frac{1}{\sqrt{2 \pi} \sigma d} \exp \left[-\frac{\ln ^{2}\left(d / d_{\text {mag }}\right)}{2 \sigma^{2}}\right]
$$

and the fit of the magnetization curves by (1) combined with (2) leads to the mean magnetic diameter $\mathrm{d}_{\mathrm{mag}}$ and the polydispersity index $\sigma$.

\section{Measurement of total iron (ICP)}

The total iron mass per spheroid was quantified by elemental analysis using inductively coupled plasma mass spectroscopy (ICP-AES, Spectro ARCOS). For each measurement, a fresh spheroid was digested in $200 \mu \mathrm{L}$ of boiling 70\% nitric acid (Sigma Aldrich, trace metals basis grade) for $1 \mathrm{~h}$ at $100^{\circ} \mathrm{C}$. The solutions were then diluted with filtered ultrapure water for analysis (in $1 \% \mathrm{HNO}_{3}$ ).

\section{Single-endosome model}


After nanoparticles incubation, cells were detached, centrifuged and re-suspended in sucrose buffer (250 mM sucrose, $3 \mathrm{mM}$ imidazole, buffered at $\mathrm{pH} 7$ or $\mathrm{pH} 4.7$ ) supplemented with $1 \mathrm{mM}$ DTT and 1/1000 protease inhibitor cocktail (PIC, Sigma). They were then pelleted again and disrupted by 20 times-extrusion through a 25G needle. Unbroken cells and nuclei were removed by centrifugation $(10 \mathrm{~min}, 700 \mathrm{~g})$. The (post-nuclear) supernatant was then placed on a magnet in order to sort the endosomes from all other cytoplasmic components. The non-magnetic fraction was thus eluted, while the magnetic fraction, containing only magnetic endosomes, was collected and resuspended in the same sucrose buffer (with PIC and DTT). This gentle procedure yields intact endosomes, with all their associated proteins and constituents ${ }^{58}$. On days 0 , $3,9,20$ and 60 after extraction, $20 \mu \mathrm{l}$ of the endosome suspension ( $0.5 \mathrm{ml}$ total) was placed in a sealed chamber $(1 \mathrm{~cm} \times 4 \mathrm{~mm} \times 50 \mu \mathrm{m})$ containing a $50-\mu \mathrm{m}$-diameter nickel rod magnetized by a $150 \mathrm{mT}$ external magnetic field and serving as an attractive micromagnet (grad $B=190 \mathrm{mT} / \mathrm{mm}$ in the window of observation). ${ }^{59}$ The velocity of single endosomes was then video-monitored (100X objective, Leica DMIRB) at 120-ms intervals. The magnetic moment of each endosome was calculated by equilibrating the magnetic force with the viscous drag, and was then converted into the mass of iron.

\section{Gene expression quantification}

Gene expression was quantified by qPCR. Total RNA was extracted from each spheroid, using the NucleoSpin RNA II kit (Macheney-Nagel). Reverse transcription into cDNA was performed using SuperScript II reverse transcriptase (Invitrogen). QPCR was performed with StepOnePlus (Applied Biosystems) using the SYBR Green reagent (Applied Biosystems). The RPLP0 gene was used as reference.

The primer sequences were:

RPLP0 fwd: 5' TGC ATC AGT ACC CCA TTC TAT CAT 3' 
RPLP0 rev: 5’ AAG GTG TAA TCC GTC TCC ACA GA 3'

FerrL fwd: 5’ CGA ATT GGC CGA GGA GAA 3'

FerrL rev: 5' GCC ACG CTG GTT TTG CAT 3'

FerrH fwd: 5’ TG GCT TGG CGG AAT TTC TGT 3’

FerrH rev: 5’ GC CCG AGG CTT AGC TTT CAT 3'

SLC40A1 (Ferroportin) fwd: 5'TGG CAT GGG TCT TGC TTT C 3'

SLC40A1(Ferroportin) rev: 5’ GGC GTA CCC TGT GGT GAT G 3'

DMT1 fwd: 5' CAT CGT GGG AGC TGT CAT CA 3'

DMT1 rev: 5' TTA TTG TTC CGG TTT ACC TGT CTA GA 3'

\section{Statistical analysis}

All values are reported as means and standard deviation (error bars). For gene analysis, Student's t-test was used to compare control and labeled cells. A confidence level of $99 \%$ was considered significant. ${ }^{* * *}$ corresponds to $\mathrm{p}$-value $<0.001$; $^{* *}$ to $\mathrm{p}$-value $<0.01$; $^{*}$ to $\mathrm{p}$-value $<0.05$. 


\section{FIGURES}

A

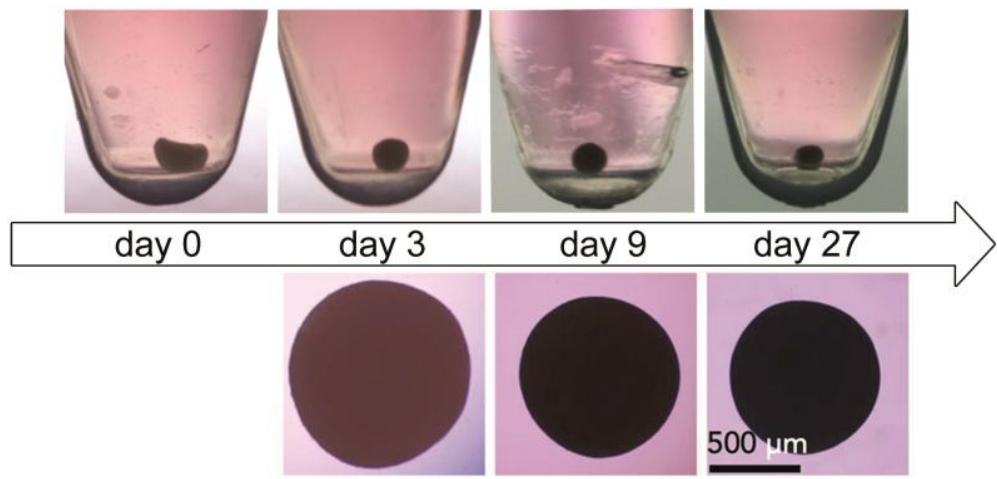

B
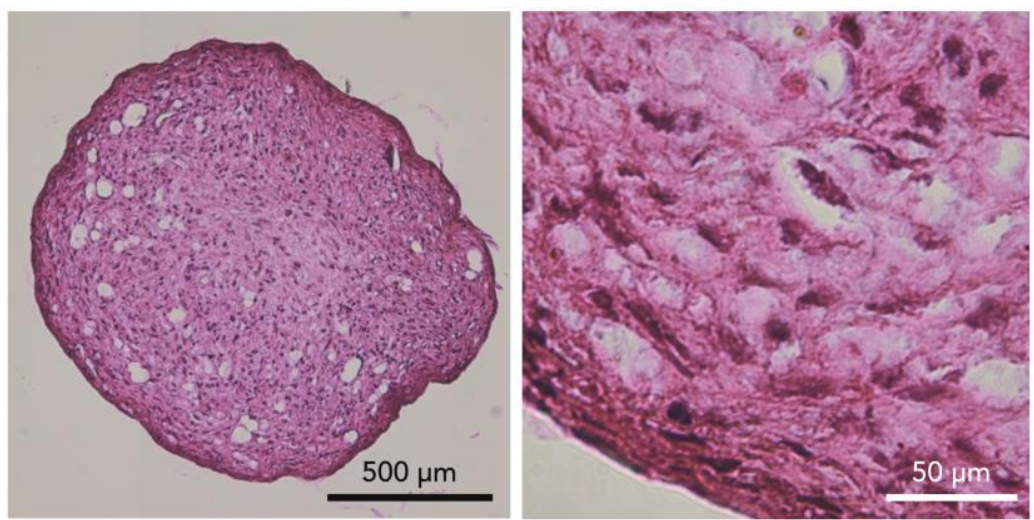

C

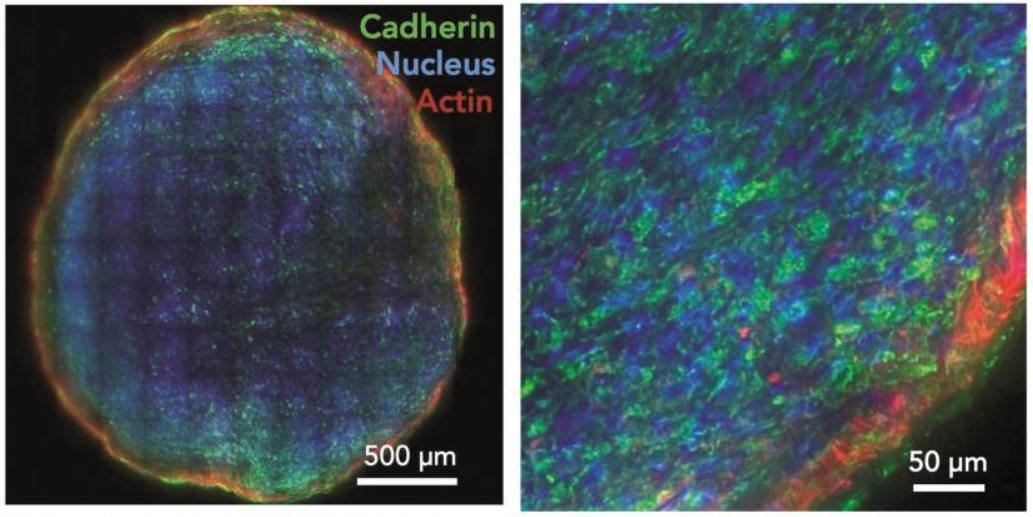

D

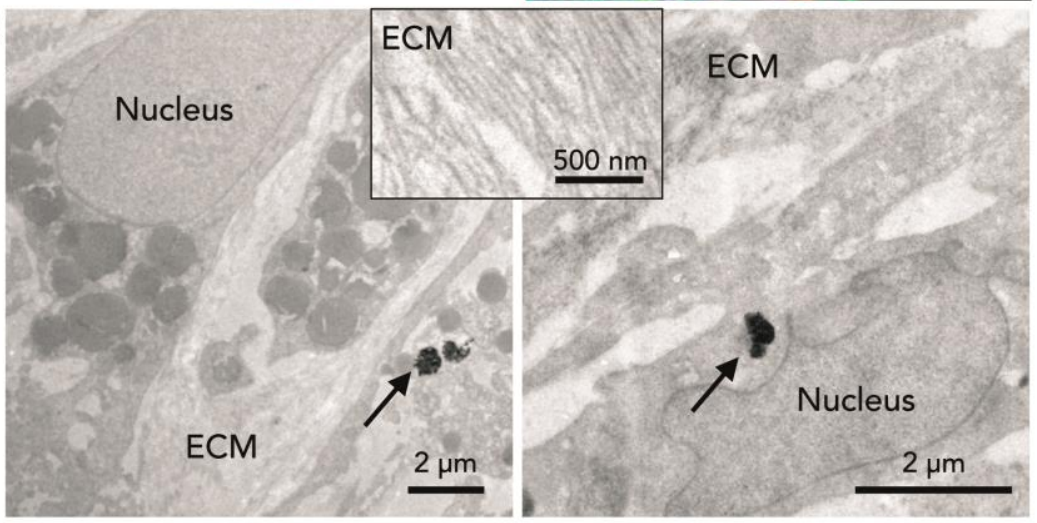

Figure 1: The stem-cell spheroid model tissue. A. Camera images of the formation and maturation of a stem cells spheroid. From day 1 to day 27 the spheroid matures and 
rounds up. Microscope images of the spheroids are shown on days 3, 10 and 27 (bottom). B. Section (16 $\mu \mathrm{m})$ of a spheroid (at 27 days) stained with hematoxylin/eosin (cytoplasm of viable cells in pink and nucleus in purple). C. Spheroid section $(30 \mu \mathrm{m})$ stained with phalloidin (actin cytoskeleton, red), with E-cadherin antibody (green) and with DAPI (nucleus,blue), 27 days after formation. D. Transmission electron microscopy (TEM) of a spheroid inner structure 27 days after formation. The cells contain endosomes filled with nanoparticles (arrows), and some extracellular matrix (ECM) surrounds the cells (zoom in the inset). 


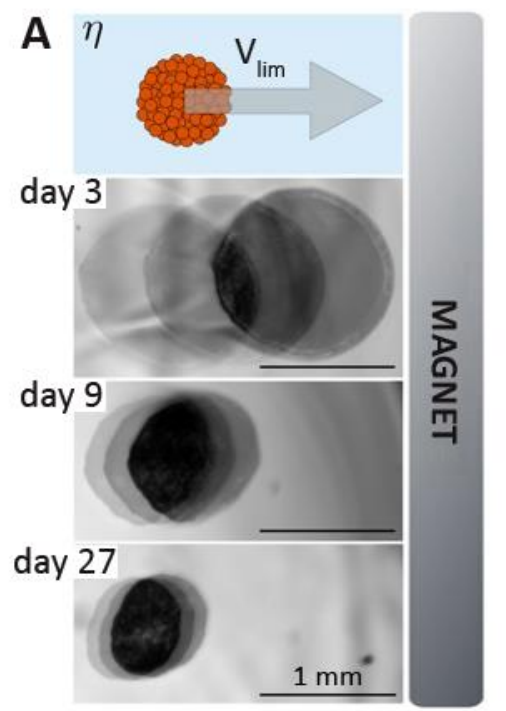

B
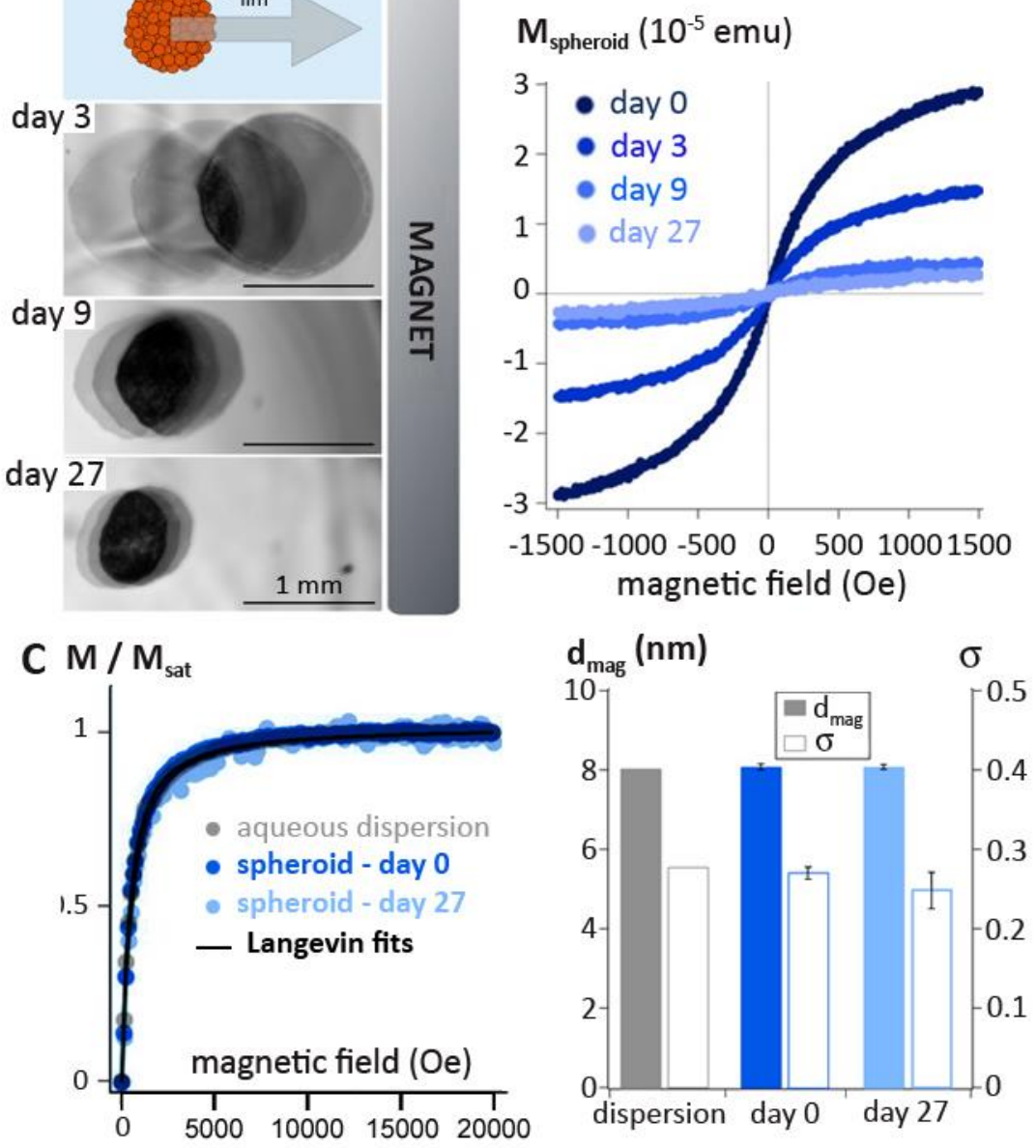

D $\mathrm{m}_{\mathrm{Fe}} / \mathrm{spheroid}(\mu \mathrm{g})$



Figure 2: Magnetism as a fingerprint of nanodegradation processes. A. Singlespheroid magnetophoresis, which consists of monitoring the magnetic attraction of the spheroid towards a permanent magnet. The magnetic velocity at equilibrium ( $\left.\mathrm{V}_{\lim }\right)$ is computed by image analysis. Three successive images of a spheroid during its migration towards the permanent magnet are superimposed (time interval $4.5 \mathrm{~s}$ ), corresponding to different maturation days. On this particular example, the limit velocities of the 
spheroid are, at day 3, 9, and 27: $94 \mu \mathrm{m} / \mathrm{s}$ (giving $\mathrm{M}_{\text {spheroid }}\left(1500\right.$ Oe)=1.6x10-5 emu / $\mathrm{m}_{\mathrm{Fe}}$ $0.24 \mu \mathrm{g}) ; 28 \mu \mathrm{m} / \mathrm{s}\left(5.3 \times 10^{-6} \mathrm{emu} / 0,09 \mu \mathrm{g}\right)$ and $19 \mu \mathrm{m} / \mathrm{s}\left(2 \times 10^{-6} \mathrm{emu} / 0,03 \mu \mathrm{g}\right)$, respectively. B. Vibrating Sample Magnetometer (VSM): typical magnetization curves obtained for a single spheroid on different days after spheroid formation. On these particular curves, the spheroid magnetic moments at 1500 0e are, at days $0,3,9$, and 27: $2.9 \times 10^{-5}$ emu $(0.46 \mu \mathrm{g}), 1,5 \times 10^{-5}$ emu $(0,22 \mu \mathrm{g}), 4.2 \times 10^{-6} \mathrm{emu}(0,06 \mu \mathrm{g})$ and $2.8 \times 10^{-6}$ emu $(0,04 \mu g)$, respectively. C. Average mass of magnetic iron (measured magnetophoresis and by magnetometry) and mass of total iron (measured by ICP) per spheroid during maturation. On the abscissa, a shift is added to facilitate the reading. At each day $(3,9$, and 27$)$, the mass decrease was found highly significant (p-value $<0.001$; t-test), compared to the mass measured at day 0. D. Renormalized magnetization curves (left) obtained for the initial nanoparticles in aqueous dispersion, of for nanoparticles within spheroids, at day 0 or day 27 , are identical, and perfectly fitted by the set of equations (1) and (2) (Langevin law pondered by lognormal size distribution, see Methods). Each condition thus provides the mean magnetic diameter $d_{\text {mag }}$ and the polydispersity index $\sigma$ (shown in the right plot). For the nanoparticles in aqueous dispersion, $\mathrm{d}_{\text {mag }}=8 \mathrm{~nm}$ and $\sigma=0.28$. For the spheroids, $\mathrm{d}_{\text {mag }}=8.1 \pm 0.1 \mathrm{~nm}$ and $\sigma=0.27 \pm 0.01$ at day 0 , and $\mathrm{d}_{\text {mag }}=8.1 \pm 0.1 \mathrm{~nm}$ and $\sigma=0.25 \pm 0.02$ at day 27 . 
A day 0
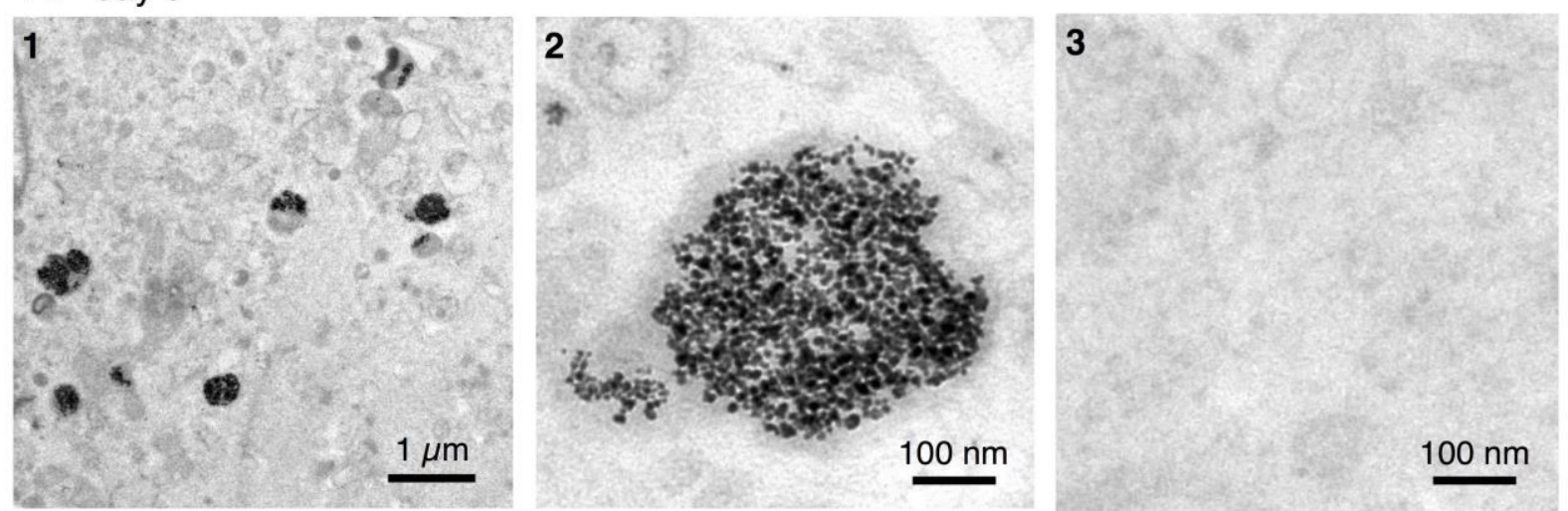

\section{B day 27}
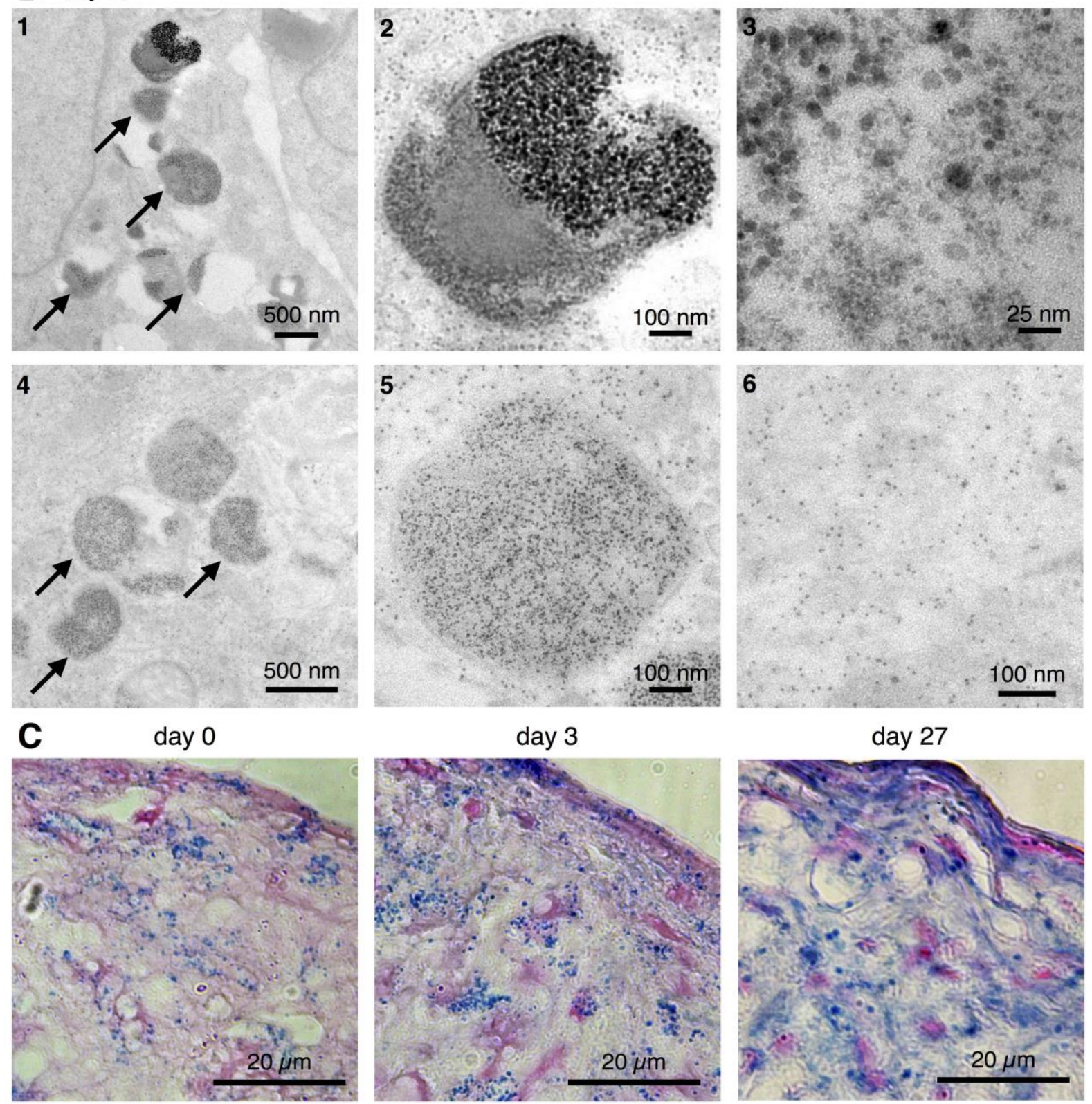

Figure 3: Nanoparticle imaging within the tissue: Evidence of nanoscale degradation. A\&B. Transmission electron microscopy of spheroid tissues containing 
nanoparticles on the day of spheroid formation (day 0) (A) and after 27 days of maturation (day 27) (B). At day 0, all the nanoparticles are confined inside endosomes (lysosomes) (A1 and A2), and no dark nanospots can be seen in the cytoplasm (A3) (see Figure S5 for additional images). At day 27, the endosomes are still filled with nanoparticles, but most of them (arrows) contain less-dark nanospots identified as ferritin. In the enlarged zones B2 and B3, the endosome is a hybrid, filled with both ferritin and intact nanoparticles. On B5 only ferritin spots remain in the endosome. Ferritin spots are also detected outside the endosomes, throughout the cytoplasm (see enlarged B6). C. Sections of spheroids at different maturation times and stained with Pearls' reagent that colors iron in blue. At day 0 and day 3, numerous small blue spots are detected throughout the cells. At day 3, a diffuse blue color starts to appear, reflecting the appearance of ferritin loaded with iron ions in the cytoplasm. At day 27, fewer blue spots are detected, while the entire cell cytoplasm is blue. 

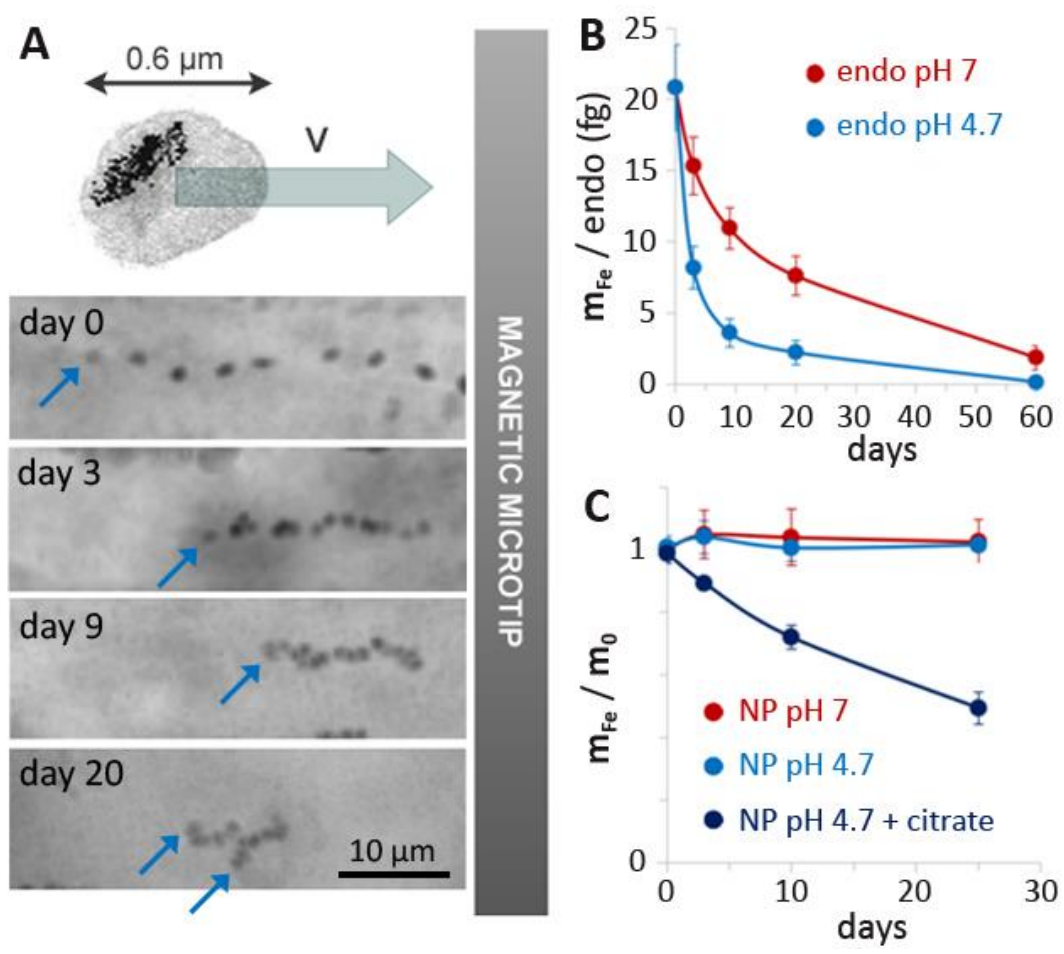

Figure 4: Collapse of magnetism at the endosomal scale, as shown by singleendosome micromagnetophoresis. A. After cell membrane rupture, magnetic endosomes were magnetically extracted from the lysate and dispersed in a reconstituted suspension. At various times after extraction (days 0 (extraction), 3, 9, 20 and 60), they were placed inside a micro-magnetophoresis chamber and submitted to the high magnetic field gradient created by a magnetic microtip. The magnetic migration of single endosomes was then tracked (here in the $\mathrm{pH} 4.7$ medium). Sequences of 15 images are superimposed, at $120 \mathrm{~ms}$ time intervals. On this particular examples, the average velocity of the endosome shown at day 0 is $34.7 \mu \mathrm{m} / \mathrm{s}$ (equivalent to $15.4 \mathrm{fg}$ of iron), while it falls to $12.6 \mu \mathrm{m} / \mathrm{s}$ (5.6 fg) at day 3; then to $8.3 \mu \mathrm{m} / \mathrm{s}$ (3.7 fg) at day 9 , and $3.4 \mu \mathrm{m} / \mathrm{s}(1.5 \mathrm{fg}$ ) at day 20 for the left-hand endosome, $3.8 \mu \mathrm{m} / \mathrm{s}$ (1.7 fg) for the right-hand endosome. First endosome of each sequence is indicated by an arrow. B. Corresponding average mass of magnetic iron per endosome (over 200 endosomes tracked for each condition) on different days in reconstituted medium at $\mathrm{pH} 7$ or $\mathrm{pH} 4.7$. All mass decreases were found significant (t-test), with p-value $<0.001$ (highly 
significant) at all days $(3,9,20$, and 60$)$ for $\mathrm{pH} 4.7$ and at days 20 and 60 for pH 7; pvalue $<0.01$ (very significant) at day 9 for $\mathrm{pH} 7$, and $\mathrm{p}$-value $<0.05$ (significant) at day 3 for $\mathrm{pH}$ 7. C. Control experiment with nanoparticles dispersed in the same media $(\mathrm{pH} 7$ and $\mathrm{pH}$ 4.7), and mass of magnetic iron measurement by magnetometry (VSM) over time. When not contained within endosomes, the nanoparticles are not degraded, unless a chelating agent (citrate, $\mathrm{pH}$ 4.7) is added (in this case, the iron mass decrease compared to day 0 was highly significant (p-value<0.001) at days 10 and 25 , and very significant (p-value $<0.01)$ at day 3$)$.
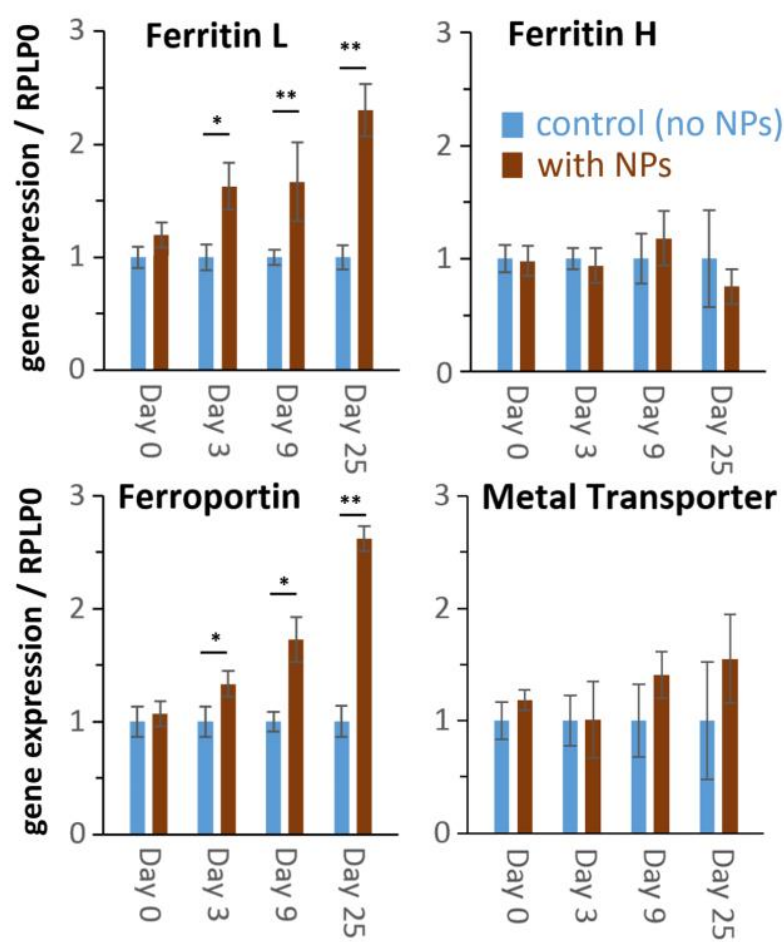

Figure 5: Impact on iron homeostasis genes. Relative expression level of genes coding for ferritin light chain (ferritin L), ferritin heavy chain (ferritin H), ferroportin, and the divalent metal transporter DMT1. Gene expression was measured at each time point for spheroids labeled with nanoparticles (NPs) and unlabeled spheroids (control). Expression was normalized to RPLP0 mRNA and expressed relative to the average control value on each day $(n=6$ spheroids for nanoparticle conditions, and $n=3$ for 
control conditions). The error bars represent the standard error of the mean. ${ }^{*}$ indicates $0.01<\mathrm{p}$-value $<0.05,{ }^{* *}$ indicates $\mathrm{p}$-value $<0.01$ in Student's t-test.


Figure 6: Degradation of nanocubes and nanodimers. A,B. Typical TEM images at the heart of a spheroid containing nanocubes (A) or nanodimers (B), at the time of 
spheroid formation (day 0) and after 27 days of maturation (day 27). C,D. Mass of magnetic (measured by VSM) and total iron on days 0 and 27, for nanocubes (C) and nanodimers (D). Total iron content was conserved, while magnetic iron fell by $26,8 \%$ with nanocubes and by $20 \%$ with nanodimers. T-student was performed between the masses measured at day 0 , and the ones at day 27 ( $^{*}$ indicate $\mathrm{p}<0.05$, ${ }^{* *}$ corresponds to $\mathrm{p}<0.01$ ). E,F. Comparison of the normalized magnetization curves, in aqueous dispersion and in spheroids at day 0 and day 27, for nanocubes (E) and nanodimers (F). The magnetization curves for nanocubes provide a signature of the local intracellular organization. As the nanocube core is ferromagnetic (blocking temperature over $310 \mathrm{~K}$ ), magnetic interactions between nanocubes are directly detected on $M(H) / M_{\text {sat. At day }} 0$, the hysteresis cycle opens (while it is closed in dispersion because the nanocubes are free to rotate), and the magnetic susceptibility decreases, demonstrating that, inside cells, the magnetic interactions are very important, and confirming the confinement inside endosomes. At day 27, we observed the same tendency, albeit with slightly larger opening of the hysteresis cycle, and magnetic susceptibility was also slightly lower than at day 0 . This indicates that, over the 27 days of tissue maturation, the nanocubes end up even more confined within endosomes than at day 0 . With nanodimers, the iron oxide core is superparamagnetic (blocking temperature below $310 \mathrm{~K}$ ), and no differences are detected between dispersed nanodimers and internalized nanodimers (day 0 or 27) on the normalized magnetization curves. Magnetic diameters and polydispersity $(\sigma)$ obtained by fitting these curves with Langevin formalism (pondered by lognormal distribution) are shown in Figure S14, and are perfectly identical, demonstrating an all-or-nothing degradation mechanism. 


\section{SUPPORTING INFORMATION}

Additional Figures S1 to S14. This material is available free of charge via the Internet at http://pubs.acs.org.

\section{AUTHOR INFORMATION}

\section{Corresponding Author}

*E-mail: claire.wilhelm@univ-paris-diderot.fr

All authors have given approval to the final version of the manuscript.

\section{ACKNOWLEDGEMENTS}

This work was supported by the European Union (ERC-2014-CoG project MaTissE 648779). Additionally, we thank Giammarino Pugliese and Simone Nitti for sample preparation.

\section{REFERENCES}

1. Bulte, J. W.; Kraitchman, D. L. Iron Oxide Mr Contrast Agents for Molecular and Cellular Imaging. NMR Biomed. 2004, 17, 484-499.

2. Naumova, A. V.; Modo, M.; Moore, A.; Murry, C. E.; Frank, J. A. Clinical Imaging in Regenerative Medicine. Nat. Biotechnol. 2014, 32, 804-818.

3. McCarthy, J. R.; Weissleder, R. Multifunctional Magnetic Nanoparticles for Targeted Imaging and Therapy. Adv. Drug Del. Rev. 2008, 60, 1241-51.

4. $\quad$ Edmundson, M.; Thanh, N. T.; Song, B. Nanoparticles Based Stem Cell Tracking in Regenerative Medicine. Theranostics 2013, 3, 573-582.

5. $\quad$ Di Corato, R.; Gazeau, F.; Le Visage, C.; Fayol, D.; Levitz, P.; Lux, F.; Letourneur, D.; Luciani, N.; Tillement, O.; Wilhelm, C. High-Resolution Cellular Mri: Gadolinium and Iron Oxide Nanoparticles for in-Depth Dual-Cell Imaging of Engineered Tissue Constructs. ACS nano 2013, 7, 7500-7512.

6. $\quad$ Bulte, J. W.; Walczak, P.; Janowski, M.; Krishnan, K. M.; Arami, H.; Halkola, A.; Gleich, B.; Rahmer, J. Quantitative "Hot Spot" Imaging of Transplanted Stem Cells Using Superparamagnetic Tracers and Magnetic Particle Imaging (Mpi). Tomography 2015, 1, 91.

7. Tang, Y.; Zhang, C.; Wang, J.; Lin, X.; Zhang, L.; Yang, Y.; Wang, Y.; Zhang, Z.; Bulte, J. W.; Yang, G. Y. Mri/Spect/Fluorescent Tri - Modal Probe for Evaluating the Homing 
and Therapeutic Efficacy of Transplanted Mesenchymal Stem Cells in a Rat Ischemic Stroke Model. Adv. Funct. Mater. 2015, 25, 1024-1034.

8. El Haj, A. J.; Glossop, J. R.; Sura, H. S.; Lees, M. R.; Hu, B.; Wolbank, S.; Griensven, M.; Redl, H.; Dobson, J. An In Vitro Model of Mesenchymal Stem Cell Targeting Using Magnetic Particle Labelling. J. Tissue Eng. Regener. Med. 2015, 9, 724-733.

9. $\quad$ Cheng, K.; Li, T.-S.; Malliaras, K.; Davis, D. R.; Zhang, Y.; Marbán, E. Magnetic Targeting Enhances Engraftment and Functional Benefit of Iron-Labeled CardiosphereDerived Cells in Myocardial Infarction. Circul. Res. 2010, 106, 1570-1581.

10. Chaudeurge, A.; Wilhelm, C.; Chen-Tournoux, A.; Farahmand, P.; Bellamy, V.; Autret, G.; Ménager, C.; Hagège, A.; Larghéro, J.; Gazeau, F. Can Magnetic Targeting of Magnetically Labeled Circulating Cells Optimize Intramyocardial Cell Retention? Cell Transplant. 2012, 21, 679-691.

11. Souza, G. R.; Molina, J. R.; Raphael, R. M.; Ozawa, M. G.; Stark, D. J.; Levin, C. S.; Bronk, L. F.; Ananta, J. S.; Mandelin, J.; Georgescu, M.-M. Three-Dimensional Tissue Culture Based on Magnetic Cell Levitation. Nat. Nanotechnol. 2010, 5, 291-296.

12. Fayol, D.; Frasca, G.; Le Visage, C.; Gazeau, F.; Luciani, N.; Wilhelm, C. Use of Magnetic Forces to Promote Stem Cell Aggregation During Differentiation, and Cartilage Tissue Modeling. Adv. Mater. 2013, 25, 2611-2616.

13. Mattix, B. M.; Olsen, T. R.; Casco, M.; Reese, L.; Poole, J. T.; Zhang, J.; Visconti, R. P.; Simionescu, A.; Simionescu, D. T.; Alexis, F. Janus Magnetic Cellular Spheroids for Vascular Tissue Engineering. Biomaterials 2014, 35, 949-960.

14. Yamamoto, Y.; Ito, A.; Fujita, H.; Nagamori, E.; Kawabe, Y.; Kamihira, M. Functional Evaluation of Artificial Skeletal Muscle Tissue Constructs Fabricated by a Magnetic Force-Based Tissue Engineering Technique. Tissue Eng. 2010, 17, 107-114. 15. Du, V.; Fayol, D.; Reffay, M.; Luciani, N.; Bacri, J.; Gay, C.; Wilhelm, C. Magnetic Engineering of Stable Rod-Shaped Stem Cell Aggregates: Circumventing the Pitfall of Self-Bending. Integr. Biol. 2015, 7, 170-177.

16. Nel, A.; Xia, T.; Mädler, L.; Li, N. Toxic Potential of Materials at the Nanolevel. Science 2006, 311, 622-627.

17. Buyukhatipoglu, K.; Clyne, A. M. Superparamagnetic Iron Oxide Nanoparticles Change Endothelial Cell Morphology and Mechanics Via Reactive Oxygen Species Formation. J. Biomed. Mater. Res. 2011, 96, 186-195.

18. Soenen, S. J.; Himmelreich, U.; Nuytten, N.; Pisanic, T. R.; Ferrari, A.; De Cuyper, M. Intracellular Nanoparticle Coating Stability Determines Nanoparticle Diagnostics Efficacy and Cell Functionality. Small 2010, 6, 2136-2145.

19. Soenen, S. J.; Nuytten, N.; De Meyer, S. F.; De Smedt, S. C.; De Cuyper, M. High Intracellular Iron Oxide Nanoparticle Concentrations Affect Cellular Cytoskeleton and Focal Adhesion Kinase - Mediated Signaling. Small 2010, 6, 832-842.

20. Chang, Y. K.; Liu, Y. P.; Ho, J. H.; Hsu, S. C.; Lee, O. K. Amine - Surface - Modified Superparamagnetic Iron Oxide Nanoparticles Interfere with Differentiation of Human Mesenchymal Stem Cells. J. Orth. Res. 2012, 30, 1499-1506.

21. Fayol, D.; Luciani, N.; Lartigue, L.; Gazeau, F.; Wilhelm, C. Managing Magnetic Nanoparticle Aggregation and Cellular Uptake: A Precondition for Efficient Stem - Cell Differentiation and Mri Tracking. Adv. Healthcare Mater. 2013, 2, 313-325.

22. Soenen, S. J.; Parak, W. J.; Rejman, J.; Manshian, B. (Intra) Cellular Stability of Inorganic Nanoparticles: Effects on Cytotoxicity, Particle Functionality, and Biomedical Applications. Chem. Rev. 2015, 115, 2109-2135. 
23. Skotland, T.; Sontum, P. C.; Oulie, I. In Vitro Stability Analyses as a Model for Metabolism of Ferromagnetic Particles $\left(\right.$ Clariscan $^{\mathrm{TM}}$ ), a Contrast Agent for Magnetic Resonance Imaging. J. Pharm. Biomed. Anal. 2002, 28, 323-329.

24. Arbab, A. S.; Wilson, L. B.; Ashari, P.; Jordan, E. K.; Lewis, B. K.; Frank, J. A. A Model of Lysosomal Metabolism of Dextran Coated Superparamagnetic Iron Oxide (Spio) Nanoparticles: Implications for Cellular Magnetic Resonance Imaging. NMR Biomed. 2005, 18, 383-389.

25. Lévy, M.; Lagarde, F.; Maraloiu, V.-A.; Blanchin, M.-G.; Gendron, F.; Wilhelm, C.; Gazeau, F. Degradability of Superparamagnetic Nanoparticles in a Model of Intracellular Environment: Follow-up of Magnetic, Structural and Chemical Properties.

Nanotechnology 2010, 21, 395103.

26. Gutiérrez, L.; Romero, S.; da Silva, G. B.; Costo, R.; Vargas, M. D.; Ronconi, C. M.; Serna, C. J.; Veintemillas-Verdaguer, S.; del Puerto Morales, M. Degradation of Magnetic Nanoparticles Mimicking Lysosomal Conditions Followed by Ac Susceptibility. Biomed. Eng. 2015, 60, 417-425.

27. Kreyling, W. G.; Abdelmonem, A. M.; Ali, Z.; Alves, F.; Geiser, M.; Haberl, N.; Hartmann, R.; Hirn, S.; de Aberasturi, D. J.; Kantner, K. In Vivo Integrity of PolymerCoated Gold Nanoparticles. Nat. Nanotechnol. 2015, 10, 619-623.

28. Feliu, N.; Docter, D.; Heine, M.; del Pino, P.; Ashraf, S.; Kolosnjaj-Tabi, J.; Macchiarini, P.; Nielsen, P.; Alloyeau, D.; Gazeau, F.; Stauber, R. H.; Parak, W. J. In Vivo Degeneration and the Fate of Inorganic Nanoparticles. Chem. Soc. Rev. 2016.

29. $\quad$ Mejías, R.; Gutiérrez, L.; Salas, G.; Pérez-Yagüe, S.; Zotes, T. M.; Lázaro, F. J.; Morales, M. P.; Barber, D. F. Long Term Biotransformation and Toxicity of Dimercaptosuccinic Acid-Coated Magnetic Nanoparticles Support Their Use in Biomedical Applications. J. Controlled Release 2013, 171, 225-233.

30. Kolosnjaj-Tabi, J.; Lartigue, L.; Javed, Y.; Luciani, N.; Pellegrino, T.; Wilhelm, C.; Alloyeau, D.; Gazeau, F. Biotransformations of Magnetic Nanoparticles in the Body. Nano Today 2016.

31. Freund, B.; Tromsdorf, U. I.; Bruns, O. T.; Heine, M.; Giemsa, A.; Bartelt, A.; Salmen, S. C.; Raabe, N.; Heeren, J.; Ittrich, H. A Simple and Widely Applicable Method to 59feRadiolabel Monodisperse Superparamagnetic Iron Oxide Nanoparticles for In Vivo Quantification Studies. ACS nano 2012, 6, 7318-7325.

32. Ruiz, A.; Gutiérrez, L.; Cáceres-Vélez, P.; Santos, D.; Chaves, S.; Fascineli, M.; Garcia, M.; Azevedo, R.; Morales, M. Biotransformation of Magnetic Nanoparticles as a Function of Coating in a Rat Model. Nanoscale 2015, 7, 16321-16329.

33. Andreas, K.; Georgieva, R.; Ladwig, M.; Mueller, S.; Notter, M.; Sittinger, M.; Ringe, J. Highly Efficient Magnetic Stem Cell Labeling with Citrate-Coated Superparamagnetic Iron Oxide Nanoparticles for Mri Tracking. Biomaterials 2012, 33, 4515-4525.

34. Rogers, W. J.; Meyer, C. H.; Kramer, C. M. Technology Insight: In Vivo Cell Tracking by Use of Mri. Nat. Clin. Pract. Cardiovasc. Med. 2006, 3, 554-562.

35. Smirnov, P.; Poirier - Quinot, M.; Wilhelm, C.; Lavergne, E.; Ginefri, J. C.;

Combadière, B.; Clément, O.; Darrasse, L.; Gazeau, F. In Vivo Single Cell Detection of Tumor - Infiltrating Lymphocytes with a Clinical 1.5 Tesla Mri System. Magn. Reson. Med. 2008, 60, 1292-1297.

36. Soukup, D.; Moise, S.; Céspedes, E.; Dobson, J.; Telling, N. D. In Situ Measurement of Magnetization Relaxation of Internalized Nanoparticles in Live Cells. ACS nano 2015, 9, 231-240.

37. Liu, X.; Theil, E. C. Ferritins: Dynamic Management of Biological Iron and Oxygen Chemistry. Acc. Chem. Res. 2005, 38, 167-175. 
38. Lartigue, L.; Alloyeau, D.; Kolosnjaj-Tabi, J.; Javed, Y.; Guardia, P.; Riedinger, A.; Péchoux, C.; Pellegrino, T.; Wilhelm, C.; Gazeau, F. Biodegradation of Iron Oxide Nanocubes: High-Resolution in Situ Monitoring. ACS nano 2013, 7, 3939-3952.

39. Gálvez, N.; Fernández, B.; Sánchez, P.; Cuesta, R.; Ceolín, M.; Clemente-León, M.; Trasobares, S.; López-Haro, M.; Calvino, J. J.; Stéphan, O. Comparative Structural and Chemical Studies of Ferritin Cores with Gradual Removal of Their Iron Contents. J. Am. Chem. Soc. 2008, 130, 8062-8068.

40. Watt, R. K.; Hilton, R. J.; Graff, D. M. Oxido-Reduction Is Not the Only Mechanism Allowing Ions to Traverse the Ferritin Protein Shell. Biochim. Biophys. Acta 2010, 1800, 745-759.

41. Balakumaran, A.; Pawelczyk, E.; Ren, J.; Sworder, B.; Chaudhry, A.; Sabatino, M.; Stroncek, D.; Frank, J. A.; Robey, P. G. Superparamagnetic Iron Oxide Nanoparticles Labeling of Bone Marrow Stromal (Mesenchymal) Cells Does Not Affect Their "Stemness". PloS one 2010, 5, e11462.

42. Geppert, M.; Hohnholt, M. C.; Nürnberger, S.; Dringen, R. Ferritin up-Regulation and Transient Ros Production in Cultured Brain Astrocytes after Loading with Iron Oxide Nanoparticles. Acta Biomater. 2012, 8, 3832-3839.

43. Hohnholt, M. C.; Geppert, M.; Dringen, R. Treatment with Iron Oxide Nanoparticles Induces Ferritin Synthesis but Not Oxidative Stress in Oligodendroglial Cells. Acta Biomater. 2011, 7, 3946-3954.

44. Gu, J.; Xu, H.; Han, Y.; Dai, W.; Hao, W.; Wang, C.; Gu, N.; Xu, H.; Cao, J. The Internalization Pathway, Metabolic Fate and Biological Effect of Superparamagnetic Iron Oxide Nanoparticles in the Macrophage-Like Raw264. 7 Cell. Science China: Life Sciences 2011, 54, 793-805.

45. Pawelczyk, E.; Arbab, A. S.; Pandit, S.; Hu, E.; Frank, J. A. Expression of Transferrin Receptor and Ferritin Following Ferumoxides-Protamine Sulfate Labeling of Cells: Implications for Cellular Magnetic Resonance Imaging. NMR Biomed. 2006, 19, 581-592. 46. Guardia, P.; Riedinger, A.; Nitti, S.; Pugliese, G.; Marras, S.; Genovese, A.; Materia, M. E.; Lefevre, C.; Manna, L.; Pellegrino, T. One Pot Synthesis of Monodisperse Water Soluble Iron Oxide Nanocrystals with High Values of the Specific Absorption Rate. J. Mater. Chem. 2014, 2, 4426-4434.

47. Pellegrino, T.; Manna, L.; Kudera, S.; Liedl, T.; Koktysh, D.; Rogach, A. L.; Keller, S.; Rädler, J.; Natile, G.; Parak, W. J. Hydrophobic Nanocrystals Coated with an Amphiphilic Polymer Shell: A General Route to Water Soluble Nanocrystals. Nano Lett. 2004, 4, 703707.

48. Kolosnjaj-Tabi, J.; Javed, Y.; Lartigue, L.; Volatron, J.; Elgrabli, D.; Marangon, I.; Pugliese, G.; Caron, B.; Figuerola, A.; Luciani, N. The One Year Fate of Iron Oxide Coated Gold Nanoparticles in Mice. ACS nano 2015, 9, 7925-7939.

49. Bouwmeester, H.; Lynch, I.; Marvin, H. J.; Dawson, K. A.; Berges, M.; Braguer, D.; Byrne, H. J.; Casey, A.; Chambers, G.; Clift, M. J. Minimal Analytical Characterization of Engineered Nanomaterials Needed for Hazard Assessment in Biological Matrices. Nanotoxicology 2011, 5, 1-11.

50. Xu, X.; Farach-Carson, M. C.; Jia, X. Three-Dimensional In Vitro Tumor Models for Cancer Research and Drug Evaluation. Biotechnol. Adv. 2014, 32, 1256-1268.

51. Hirschhaeuser, F.; Menne, H.; Dittfeld, C.; West, J.; Mueller-Klieser, W.; KunzSchughart, L. A. Multicellular Tumor Spheroids: An Underestimated Tool Is Catching up Again. J. Biotechnol. 2010, 148, 3-15. 
52. Mazuel, F.; Reffay, M.; Du, V.; Bacri, J.-C.; Rieu, J.-P.; Wilhelm, C. Magnetic Flattening of Stem-Cell Spheroids Indicates a Size-Dependent Elastocapillary Transition. Phys. Rev. Lett. 2015, 114, 098105.

53. Huang, K.; Ma, H.; Liu, J.; Huo, S.; Kumar, A.; Wei, T.; Zhang, X.; Jin, S.; Gan, Y.; Wang, P. C. Size-Dependent Localization and Penetration of Ultrasmall Gold Nanoparticles in Cancer Cells, Multicellular Spheroids, and Tumors In Vivo. ACS nano 2012, 6, 4483-4493.

54. Wang, Y.; Bahng, J. H.; Che, Q.; Han, J.; Kotov, N. A. Anomalously Fast Diffusion of Targeted Carbon Nanotubes in Cellular Spheroids. ACS nano 2015, 9, 8231-8238.

55. Vörsmann, H.; Groeber, F.; Walles, H.; Busch, S.; Beissert, S.; Walczak, H.; Kulms, D. Development of a Human Three-Dimensional Organotypic Skin-Melanoma Spheroid Model for In Vitro Drug Testing. Cell Death Dis. 2013, 4, e719.

56. Ho, D. N.; Kohler, N.; Sigdel, A.; Xu, C.; Sun, S.; Morgan, J. R.; Kalluri, R. Penetration of Endothelial Cell Coated Multicellular Tumor Spheroids by Iron Oxide Nanoparticles. Theranostics 2012, 2, 66-75.

57. Yu, H.; Chen, M.; Rice, P. M.; Wang, S. X.; White, R.; Sun, S. Dumbbell-Like Bifunctional Au-Fe3o4 Nanoparticles. Nano Lett. 2005, 5, 379-382.

58. Loubéry, S.; Wilhelm, C.; Hurbain, I.; Neveu, S.; Louvard, D.; Coudrier, E. Different Microtubule Motors Move Early and Late Endocytic Compartments. Traffic 2008, 9, 492509.

59. Andriola Silva, A. K.; Di Corato, R.; Gazeau, F.; Pellegrino, T.; Wilhelm, C. Magnetophoresis at the Nanoscale: Tracking the Magnetic Targeting Efficiency of Nanovectors. Nanomedicine 2012, 7, 1713-1727. 